\title{
Impact of nanotoxicology towards technologists to end users
}

\author{
Chan Oeurn Chey ${ }^{1 \S}$, Hirak K Patra ${ }^{2 \S}$, Mattias Tengdelius ${ }^{3 \S}$, Mohsen Golabi ${ }^{2 \S}$, Onur Parlak ${ }^{2 \S}$, \\ Roghayeh Imani ${ }^{2,4 \S}$, Sami A. I. Elhag ${ }^{1 \S}$, Wetra Yandi ${ }^{5 \S}$ and Ashutosh Tiwari ${ }^{2 \star}$ \\ ${ }^{1}$ Division of Physics and Electronics, ITN-Linköpings universitet, Norrköping 60174, Sweden \\ ${ }^{2}$ Biosensors and Bioelectronics Centre, IFM-Linköpings universitet, Linkoping 58183, Sweden \\ ${ }^{3}$ Organic Chemistry, IFM-Linköping University, 58183 Linköping, Sweden \\ ${ }^{4}$ Biophysics Laboratory, Faculty of Electrical Engineering, University of Ljubljana, 1000 Ljubljana, Slovenia \\ ${ }^{5}$ Division of Molecular Physics, IFM-Linköping University, Linköping 58183, Sweden
}

$\S$ Authors contributed equally and all names arranged in alphabetical order.

*Corresponding author. E-mail: ashutosh.tiwari@liu.se; Tel: (+46) 13282395; Fax: (+46) 13137568

Submitted: 10-06-2013, Revised: 24-06-2013 and Accepted: 28-06-2013

\section{ABSTRACT}

The length scale for nanomaterial is small enough to be invisible and presume innocence for the initial avoidance of the toxicity issues. Again it was beyond the understanding of the time frame when nanotechnology just blooms that a length scale itself might be an important toxic parameter apart from its materialistic properties. We present this report to address the fundamental issues and questions related to the nanotoxicity issues from laboratory to the land of applications. We emphasize about the basic nanoscale materials that are regularly being used by the scientific community and the nanotechnology based materials that has already in the market or will come soon. Copyright (C) 2013 VBRI press.

Keywords: Nanomaterials; nanotoxicity; nanotoxicology.

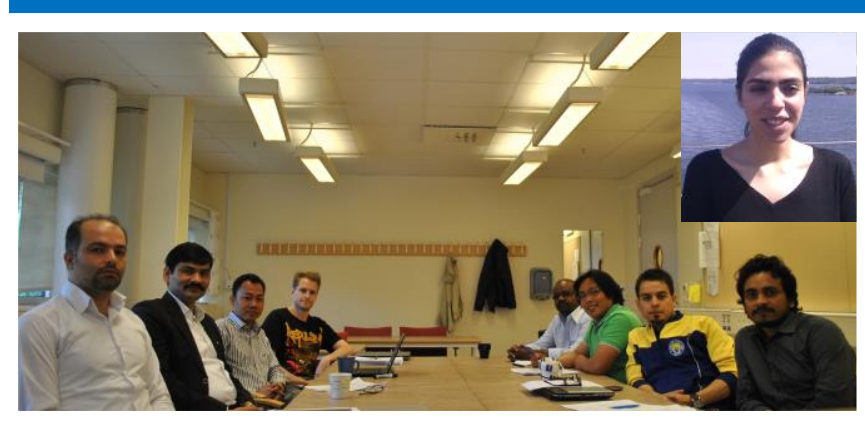

Left side: Mohsen Golabi, Ashutosh Tiwari, Chan Oeurn Chey, Mattias Tengdelius; Right side: Hirak K Patra, Onur Parlak, Wetra Yandi, Sami A. I. Elhag; and Inset: Roghayeh Imani

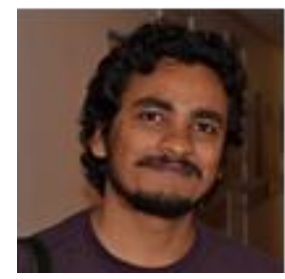

\section{Course Lecturer: Hirak K Patra}

Hirak is an Integrative Regenerative Medicine (IGEN) Post-Doctoral Fellow at Biosensors and Bioelectronics Center of the division of Applied Physics in Linköping University. He received his $\mathrm{PhD}$ from University of Calcutta, India in the area of Nanomedicine and Nano-biotechnology. He is exploring smart cell selective module for targeting and therapy of cancer alongside with his innovative label free approach for detection of individual cell type. He has been awarded IAAM Young scientist Award last year in 2012 for his outstanding contribution at the nano-bio interface.

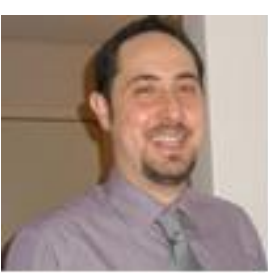

Course Lecturer: Valerio Beni

Valerio has received his Ph.D. from the University College Cork (UCC), Ireland. $\mathrm{He}$ is expert in the design and application of micro-fabricated electrode arrays for the detection of heavy metals in environmental samples In September 2011 he moved to the Linkoping University, Sweden as an Assistant Professor in the "Biosensors and Bioelectronics Centre". During his carrier Dr. Valerio Beni has been awarded a Marie Curie Intra-European Fellowships (EIF) and Marie Curie European Reintegration Grants (ERG).

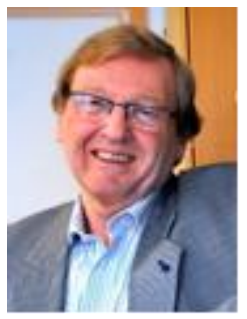

Course Professor: Anthony PF Turner

Professor Turner's name is synonymous with the field of Biosensors and in 2010 he joined IFM-Linköping to create a new Centre for Biosensors and Bioelectronics. His previous thirty-five year academic career in the UK culminated in the positions of Principal of Cranfield University at Silsoe and Distinguished Professor of Biotechnology. Professor Turner has over 750 publications and patents in the field of biosensors and biomimetic sensors and presented well over 400 keynote and plenary lectures at a range of international meetings and honour ceremonies around the world. He co-founded and has edited the principal journal in the field, Biosensors \& Bioelectronics, since 1985 and edited the first textbook on Biosensors in 1987. 


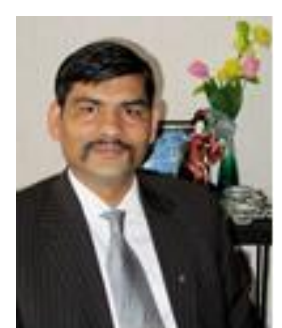

Course coordinator \& examiner: Ashutosh Tiwari

$\mathrm{He}$ is associate professor at the world premier Biosensors and Bioelectronics Centre, Linköping University, Sweden; Secretary General, International Association of Advanced Materials. Dr. Tiwari obtained various prestigious fellowships including JSPS (regular and bridge fellow), Japan; SI, Sweden; and Marie Curie, England/Sweden. In his academic carrier, he has published over 200 articles, patents and conference proceedings in the field of materials science and technology. He edited/authored fifteen books on the advanced state-of-the-art of materials science with several publishers. He availed 'The Nano Award' and 'Innovation in Materials Science Award and Medal'.

\section{Course Contents:}

http://www.ifm.liu.se/edu/graduate/courses/PhD-Course-IBMDAshutosh-Tiwari.pdf

\section{Study report}

Nanomaterials are individual blocks of a material of sizes in the range of $1-100 \mathrm{~nm}$ and constitute the base to a revolution in all fields under the name nanotechnology [12]. It has attracted great attention to many applications due to their extraordinary physical and chemical, mechanical, magnetic, optical, electrical and piezoelectric properties compared to bulk materials, which offer great promise in the development of nanotechnology to revolutionize the world through promising applications, including industry, agriculture, business, medicine, public health, household appliances, and environment [3-4]. In particular, nanomaterial have been used in drug delivery, disease detection, and disease treatment applications such as medical imaging, medicine and dentistry, treatments medical device, implantable sensors, drug delivery and dermatology [5-7]. Moreover, nanomaterials have been integrated for electromechanical and flexible devices, tissue engineering, devices for monitoring cellular signals and Hybrid nano-bio-mechanical system [7-9].

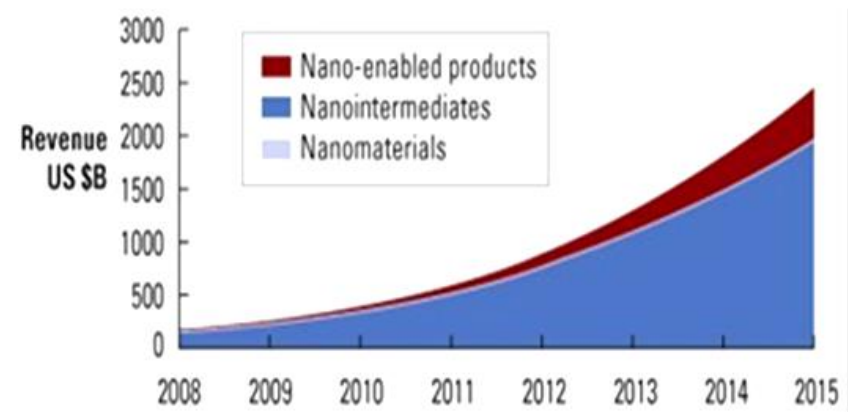

Fig. 1. Nanotech revenue is predicted to reach $\$ 2500$ billion in 2015. Reproduced from [16].

The world economy has been significantly affected due to activities related to nanotechnology [10-12]. Fig. 1 shows enormous revenue of $\sim \$ 2500$ billion that is expected to prevail by 2015 in relation to nanotechnology enabled products. Nanotechnology is growing by leaps and bounds; there are a lot of materials, tools, devices, as well as inventories of nanotechnology based consumer product as described in details in [13-14]. However, Nanotechnology already is part of our life. Therefore several questions have started to arise e.g., is this technology benign? How about their interactions with cells or human organisms? How would be the regulations on a scale? [15-16]

Considering the above questions and summarizing the possible hazards of nanoparticles (NPs) there will be a future need for analyzing the presence and properties of NPs in samples from humans, animals, the environment and commercial products. Such routine analyses needs to be user-friendly, robust and standardized to allow for a costeffective flow of various NP-containing samples. The development of routine analytical techniques for the detection and characterization of NPs do however face two major problems. The first is the isolation of the NPs. Collection, filtering and extraction of the NPs has shown to be associated with aggregation thus giving false data in the subsequent characterization steps. NPs special chemical and physical properties have previously not been a factor accounted for when developing the techniques for filtering and chromatography used as standards today. The stability index of the nanoparticle in this aspect is another important issue needs to be addressed [17-18]. The need for isolating both metallic and organic NPs from the same samples means facing another challenge previously unmet. Thus, the development of techniques for isolation of NPs from a wide range of samples without the undesirable aggregation is a first necessary step for analyzing the presence of NPs in our surroundings [19].

The second problem lies in combining the desired analysis techniques needed for characterizing unknown NPs to a simple standard protocol [19]. Characterization of the elemental composition, size, shape and quantity of the NPs are all needed to evaluate their potential hazardous implications. These properties can all be characterized today using different methods such as TEM, ICP-MS, XPS and DLS. These methods are often costly, time-consuming and each requires their degree of expertise. Sometimes prior knowledge of the content of the sample is needed as well. The choice of technique also varies depending on whether metallic or organic NPs are being analyzed. Additionally, some protocols used today rely on a fair degree of purity of the sample. Finding simple robust techniques for analyzing multiple factors in mixed samples without relying on the technical expertise of the user is thus of utmost importance. New scopes on the implications of NPs are continuously published and we steadily begin to acquire some fundamental knowledge on their impact on humans, animals and the environment. The research on routine analyses for detection and characterization of NPs are however virtually nonexistent and given the challenges described this is a trend that needs to change now.

Among the nanomaterial series, metal oxide nano is one of the promising materials have been applied in many applications such as chemical sensors and biosensors, cancer immunotherapy, water treatment, pollution trace detection and environmental improvement, sensors for environmentally hazardous gases. Furthermore, metal oxides based piezoelectric humidity sensors and 
piezoelectric nanogenerators based devices for converting mechanical energy (such as body movement, muscle stretching, blood pressure, flow of body fluids, blood flow, contraction of blood vessels, dynamic fluid in nature) into electrical energy are also possible applications for selfpowering nanodevices and nanosystems for implantation of nanodevices [20-23]. However, since almost everything can be toxic at an enough dose and nanomaterials behave with different properties at different size and shape for different compound classes, including metals, metal oxides, carbon, and semiconductor nanomaterials [24-27]. Therefore, the potential negative impacts of nanomaterials on human health and the environment of nanotechnology have become an increasingly active area of research.

Carbon based nanostructured materials also have been attracted considerable attention in recent years due to their fascinating mechanical, electrical, thermal and optical properties. They have been widely used in biological and medical technologies and for a variety of biomedical areas ranging from biosensing, drug delivery, cancer treatment, tissue engineering where the requirement of safety and toxicity is priority [28]. Due to their biocompatible property, they have been commonly used for these applications. However, safety and toxicity issues have not been solved yet and stayed as a question mark [29]. Here, we highlighted safety and toxicity issues of carbon based materials, mainly focusing on graphene and carbon nanotubes.

The diagnostic and therapeutic applications based on carbon nanotubes (CNTs) have been seen as intriguing issues and have recently started to be investigated in environmental, health and safety perspectives [30]. The preliminary results of some studies showed that CNTs are biologically compatible to certain cells and organs however some further studies indicated that CNTs are extremely hazardous that can cause both acute and chronic adverse effects to most of the living system [31-32]. Though the cellular uptake of CNTs, mechanisms of cytotoxic and how it's modulated by physicochemical parameters (diameter, length, surface functionalization etc.) are still unclear and needed to be investigated more precisely. It is apparent that, biological effects of CNTs should be considered as sample and case specific. Therefore, the nanotoxicity and safety require continuing and extensive investigations before clinical and biomedical applications.

Although biological-related applications, especially in vivo applications have been taken to ensure for CNTs, a very few studies are available for graphene. Analogously, the toxicity of graphene also depends on some physicochemical parameters. Recently, Zhang et al. compared that, cytotoxicity of graphene to that of CNTs in neuronal PC12 cells [33]. The results showed that toxicity of graphene is size and shape dependent, with having a lower toxicity than CNTs. However in lower concentrations, graphene showed inverse effect between toxicity and concentrations. The other recent study showed that, surface modified graphene nanosheets can be used for photothermal cancer treatment without any adverse effect in toxicity perspective [34]. Although many successful and promising applications have been reached, more detailed and longer-term studies are required before serious in vivo biomedical applications of graphene. As a result, there are many challenges ahead that must be addressed before CNTs and graphene can be successfully integrated into biomedical devices and technology. The main advances required, in our opinions, include the following:

i. Protocols and fur their experiments should be conducted to determine the exact nature of the nanotoxicity of CNT-based and graphene-based materials.

ii. Innovative ideas and further experiments are needed to further develop the use of graphene in advanced biomedical applications.

iii. Innovative solutions are required to reduce fabrication and running costs of CNT and graphene biomedical devices to make them economically viable.

iv. The long-term goals associated with incorporating CNTs and graphene into biomedical technology suggest that further research is required before these carbon nanostructured devices reach sufficient performance standards.

Another aspect of metal-based nanoparticles is in biomolecular and biomedical imaging, for example, fluorescence nanoparticles for optical imaging and magnetic nanoparticles for magnetic resonance imaging. Quantum dots and gold nanoparticles have been widely used in optical imaging due to the efficient labeling of biomolecules, cells and tissues. One successful example of the use of fluorescence nanoparticle for in vivo imaging application is cardiovascular system imaging [35]. Gold nanoparticles have been developed to improve some bio imaging devices including Optical Coherence Tomography (OCT), imaging Surface Plasmon Resonance (iSPR), Fluorescence and Raman Spectroscopy. Excellent probe of Magnetic nanoparticles have shown high spatial resolution and great anatomical detail.

Recently, study on the assessment of the potential health and environmental risk of metal-based nanomaterials has become important to their increasing production and use. Bianary quantum dot that contains cadmium/selenide has been reported to be toxic to the cell [36]. Thick coatings that increase the diameter of probe are required. Numbers of cell assays studied have been reported in concern to the interaction between nanoparticle and living substances. However, no validated standard or protocol has yet been established. There are also numbers of scientific report concerning the toxicity some metal nanoparticles yet the conclusions seem to be non-consistent. This might due to no standard protocol for assessment of nanomaterials.

The oxide form of the metal nanoparticles is equally potential for inducing toxicity to the environment, and human health that have raised concerns. The toxicological effects of nanomaterial and bulk material of $\mathrm{ZnO}, \mathrm{TiO}_{2}$ and $\mathrm{Al}_{2} \mathrm{O}_{3}$ nanoparticles have been studied on zebrafish embryos and larvae. The different concentration of the $\mathrm{ZnO}, \mathrm{TiO}_{2}$ and $\mathrm{Al}_{2} \mathrm{O}_{3}$ materials have been exposed to different wells and each well contained only one embryo in order to study of the effect of the size and dose on the zebrafish embryos and larvae. The studies found that both $\mathrm{ZnO}$ nanoparticles and bulk $\mathrm{ZnO}$ delayed zebrafish embryo and larva development, decreased their survival and hatching rates, and caused tissue damage with dose- 
depending property. But no significant toxicities to zebrafish embryos and larvae have been observed from the $\mathrm{TiO}_{2}$ and $\mathrm{Al}_{2} \mathrm{O}_{3}$ [37]. The phytotoxicity effects of $\mathrm{CuO}$, $\mathrm{NiO}, \mathrm{TiO}_{2}, \mathrm{Fe}_{2} \mathrm{O}_{3}$ and $\mathrm{Co}_{3} \mathrm{O}_{4}$ nanoparticles on lettuce, radish and cucumber seeds based on seed germination and root elongation have been investigated. The seeds were incubated with different metal oxide nanoparticles at various concentrations. The results shown that $\mathrm{CuO}$ and $\mathrm{NiO}$ have deleterious potentially impacted on the activities the seeds with dose-depending property, while $\mathrm{TiO}_{2}, \mathrm{Fe}_{2} \mathrm{O}_{3}$ and $\mathrm{Co}_{3} \mathrm{O}_{4}$ did not shown any significant phytotoxicity effects on the seeds. But at certain concentration of $\mathrm{Co}_{3} \mathrm{O}_{4}$ nanoparticle provided the improvement of the root elongation of radish seedling [38]. The comparative studies the on the cytotoxicity, oxidative stress and genotoxicity effects of carbon black, single wall carbon nanotube, $\mathrm{SiO}_{2}$ and $\mathrm{ZnO}$ nanoparticles on the mouse embryo fibroblast cells (BALB/3T3) depending on particle size, shape and composition. The different concentrations of nanoparticle suspensions with the culture medium were applied to the cells. Then the dose-dependent cytotoxicity, reactive oxygen species generation, intracellular oxidative stress levels and DNA damage have been investigated. The results shown that $\mathrm{ZnO}$ induced much greater cytotoxicity than non-metal nanoparticles, indicating that the oxidative stress may be a key route of the cytotoxicity and particle composition probably played a primary role in the cytotoxic effects of different nanoparticles and the potential genotoxicity might be mostly attributed to particle shape but $\mathrm{ZnO}$ nanoparticles induced less DNA damage compared with carbon nanotubes. There were no significant effects have been observed for $\mathrm{CB}$ and $\mathrm{SiO}_{2}$ nanoparticles [39].

The nanotoxicity of transition metal oxide nanoparticles also have been reviewed, including for vitro studies. From the investigation in mechanisms of nanotoxicity, transition metal oxide nanoparticles toxicity is compellingly related to oxidative stress and alteration of calcium homeostasis, gene expression, pro-inflammatory responses, and cellular signaling events and toxicity is a non-linear function of multi-variables. While physicochemical properties may include element specific surface catalytic activity, nanoparticle uptake, or nanoparticle dissolution [40]. The human safeties based on metal oxide nanomaterials have also been investigated. The physicochemical properties of metal oxide and their interaction with biological media are studied. The studies suggest that hazard potential is depends on a combination of material properties. Reactive oxygen species generation, fiber shape, size, solubility and crystalline phase of nanomaterials are the key of biological impact and the hazard potential decreases in the order $\mathrm{CeO}_{2}$, $\mathrm{ZnO}>\mathrm{TiO}_{2}>$ functionalized $\mathrm{SiO}_{2}>\mathrm{SiO}_{2}, \mathrm{ZrO}_{2}$ [41]. From the above studies, we can conclude that the nanotoxicity of metal oxides depending on the combination of physicochemical properties such as dose, shape, size, solubility and crystalline phase of nanomaterials. The levels of nanotoxicity are different from one metal oxide to another. For human health and environment safety, risk assessment for human and environmental is needed. However, the extent of hazard and exposure can determine the risk potential. Therefore, exposure to environment and human and hazard properties of nanomaterials must initially identified then the assessment of safety of chemical, plant, biodiversity, food, drugs, medical devices is very important in order to understand the environmental, health, and safety impacts from metal oxide nanomaterials.

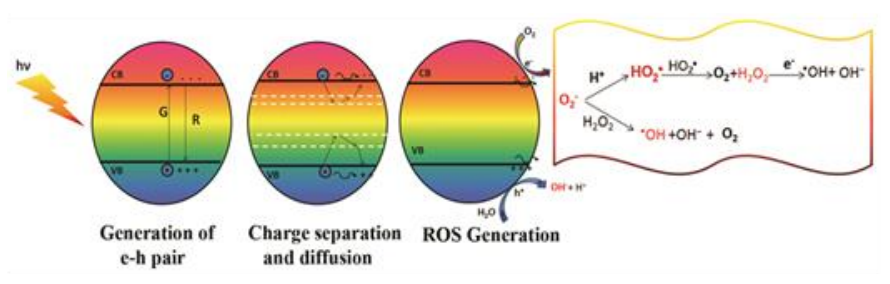

Fig. 2. Photo-induced ROS generation from metal oxide nanoparticles.

It has been reported that, the thermodynamically stable forms of most of the metals are their oxides [42]. More importantly, metal oxides such as $\mathrm{SiO}_{2}, \mathrm{TiO}_{2}, \mathrm{ZnO}$, have been considered to be 'GRAS' (generally recognized as safe) substance by United states food and drug administration (FDA) for decades [43]. Metal oxide are photoactive, the photoactivity of these materials are enhanced when their size is confined at submicron scale. With nanotechnology progress, nanocrystalline metal oxides are being used within a great variety of applications due to their novel optical, magnetic, and electronic properties [44]. With widespread use of these manufactured nanoparticles, concerns about their potential impact on the environment and human health have been raised [45].

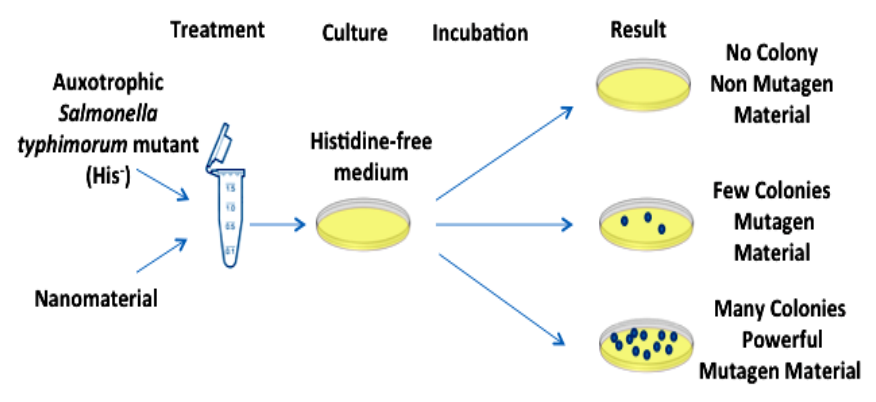

Fig. 3. Ames test.

Toxicity of manufactured nanoparticles may be attributed to several different modes of action: chemical toxicity based on chemical composition (e.g., release of toxic ions); surface catalyzed reactions (e.g., formation of reactive oxygen species (ROS)); or stress of stimuli caused by the surface, size, and shape of the particles. Photogeneration of ROS by metal oxides generally involves four processes: [46-48] (i) generation of electrons and holes by photoexcitation; (ii) migration of the photogenerated charge carriers to the surface; (iii) subsequent reduction/oxidization of the adsorbed reactants directly by electrons/holes for reactive oxygen species (ROS) forming; and (iv) recombination of the photogenerated electron-hole pairs. Phtoenerated ROS by nanocrystalline metal oxides interacting with environmental agents represents another important mode of toxicity (Fig. 2). High concentration of ROS photogenerated by nanocrystalline metal oxides causes oxidative stress and can eventually elicit toxicity in 
biological systems [49]. Wealth of studies have demonstrated phototoxicity of metal oxide nanoparticles in a broad range of biological systems, from bacteria [50] to mammalian cell lines [51]. The shape, size, and morphology of a compound can also play a significant role in its phototoxicity of nanocrystalline metal oxide [52].

Productions of nanomaterial for use in different crops have been dramatically increasing from past decade. For instance, only the amount of metal oxides nanoparticle used in skin care products had been estimated more than 1,000 tonnes in 2011 [53]. Proportional using the products, nanomaterial enter the environment and have potential to effect on ecosystem. Therefore, the toxicity and risks of nanomaterial need to be evaluated before production in industrial scale or using [54]. Nanomaterial toxicity evaluation by using of bacteria could determine the potential impact of these products in the environment. Moreover, rapid and low cost of these tests are two advantages of using bacteria as a model for nanotoxicity (Fig 3). The most common tests have been used for nanotoxicity evaluation are:

i. Growth inhibition-based nanotoxicity tests: Plating methods and spectrophotometric methods have been used for determination of minimal inhibitory concentration (MIC), lowest concentration of toxic nanoparticle that will inhibit the visible growth of bacteria, and minimal bactericidal concentration (MBC), lowest concentration of toxic nanoparticle required to kill a particular bacterium. Indeed, MIC test measure the effects of nanomaterial on general metabolic activity, while MBC test measure the amount of viability after exposure with toxic nanomaterial. There is possibility to compare different toxic impact of nanomaterial by using MIC and MBC test methods [55].

ii. Bioluminescence-based nanotoxicity tests: a few bacterial species have ability to emit bright bioluminescence in specific conditions. The intensity of the light relates to the metabolic activity of the bacterial population and density. In presence of any toxic material, the bioluminescence intensity decreases [56]. Nanotoxicity test based on their bioluminescence inhibition is a rapid test to evaluate of nanotoxicity [57]. Actually, in this method luminous bacteria used as a biosensing element to measure nanotoxicity. This test successfully set up to assess nanotoxicity in 15 minutes and its results comparable to other standard methods [58].

iii. Mutation-based nanotoxicity tests: Some nanomaterial show mutagenic activities which indicate the need of mutation-based nanotoxicity tests. Ames test [59] and Mutatox [60] test, based on using bacteria to determine mutagenic properties of compounds, has potential to use for mutation-based nanotoxicity tests [61-62]. An auxotrophic Salmonella typhimorum mutant, carry mutations in histidine pathway genes, use as a biosensing elements. Mutagen nanomaterial causes certain mutations that can result in a reversion back to a prototrophic state. So, the bacterial cells are able to growth on histidine-free medium.
Finally, major breakthroughs in nanotechnology give it an escape velocity from laboratory to "absolute world". As we want to keep continuing our world green the upcoming concept are coming to use nanomaterials to enhance the environmental sustainability and considering as the green nanotechnology. The very first step of which is to make nanoscale products using nanotechnology in support of sustainability in terms of human health and environment [63-64]. Now it's well known that the biocompatibility, bioretention, and biodistribution of nanomaterials do not agree with the rapid pace of manufacturing numerous forms of engineered nanostructures. The present efforts even limited and focused predominantly on exploring novel structures at the nanoscale rather than the novel approaches to make it "greener", where immediate steps are the demand of the time.

The other concern is, several studies are going in vitro and in vivo with cancer cells [65-67] but unfortunately, the reports are very limited for nanoparticle interactions with blood cells in circulations. There are some important aspects of such interactions are coming out e.g., interactions of red blood cell (RBC) membranes with different nanoparticle sizes and surface properties for hemocompatibility [68] and the direct interaction of hemoglobin with the nanomaterials [69]. Again it should be noted although RBCs are the majority populated cells in blood, the interactions of nanoparticles with other blood cells and their constituents should be investigated to estimate the safety use of the nanomaterials for biomedical applications [70-75].

\section{Conclussion}

The recent advances in nanoscience and nanotechnology led us to the development of the new generations of products that includes daily life use of nanomaterials to nanodevices for cosmetics to diagnostic as well as therapeutics. But the matter of fact is same unique physicochemical properties that make the glorious may participate with their potentially harmful effects on environment and health. The present report is an attempt to demonstrate the two sides of the same coin might not be in concert for the betterment of human life. Most important issue is that while we are writing this article, it remains to be under investigated whether unique electronic, chemical and redox properties of various beautiful nanostructures welcoming into unusual and unknowing deleterious effects on human health and environment for short and long term.

\footnotetext{
Acknowledgements

The authors gratefully acknowledge to Prof. Per-Olof Holtz, Director of Graduate Studies; and Prof. Stefan Klintström, Programme Director and Director of Studies, Doctoral Programme (Forum Scientium), Linköping University, Sweden for encouraging the course.

\section{Reference}

1. Drexler, K. Eric. Nanosystems: Molecular Machinery, Manufacturing, and Computatin. 1992.

ISBN: $978-0-471-57518-4$

2. Nouailhat, A. An Introduction to Nanoscience and Nanotechnology. 2008, Wiley, US.

DOI: $10.1002 / 9780470610954$

3. Wilkinson, J. M. Medical device technology, 2003, 29. DOI: $10.1002 / 9780470610954$
} 
4. Salamanca-Buentello, F.; Persad, D.; Court, E.; Martin, D.; Daar, A. PLoS Medicine. 2005, e97.

DOI:10.1371/journal.pmed.0020097

5. Patra, H.; Dasgupta, A.; Sarkar, S.; Biswas, I.; Chattopadhyay, A. Cancer Nanotechnology. 2011 2, 37.

DOI: $10.1007 / \mathrm{s} 12645-010-0011-3$

6. Holm, B.; Bergey, E.; De, T.; Rodman, D.; Kapoor, R.; Levy, L. \& Prasad, P. Molecular Crystals and Liquid Crystals. 2002, 374, 589. DOI: $10.1080 / 713738279$

7. Patra, H. and Dasgupta, A. Nanotechnology: Perspectives in the Diagnosis and Treatment of Cancers, 2012, Narosa (India), 3, 27. ISBN: $978-81-8487-159-3$.

8. Tiwari, A. and Tiwari A. Nanomaterials in Drug Delivery, Imaging, and Tissue Engineering, John Wiley \& Sons (USA), 2013. DOI: $\underline{10.1002 / 9781118644591}$

9. Tiwari, A.; Mishra, A.; Kobayashi, H. and Turner, A. Intelligent Nanomaterials. John Wiley \& Sons (USA), 2012.

DOI: $10.1002 / 9781118311974$

10. Hullmann, A. The economic development of nanotechnology-An indicators based analysis. 2006, EU report.

WEB: http://cordis.europa.eu./nanotechnology

11. Becker, S. Journal of Nanoparticle Research, 2013 15, 1. DOI: $\underline{10.1007 / \mathrm{s} 11051-013-1426-7}$

12. Roco, M.; Mirkin, C.; Hersam, M. Nanotechnology Research Directions for Societal Needs in 2020. 2011, XLI, 690.

ISBN: 978-94-007-1168-6

13. Kimbrell, G. Nanotech. L. \& Bus. 2006, 3, 329.

WEB:

http://www.nanolabweb.com/index.cfm/action/main.default.viewArti cle/articleID/152/CFID/6106232/CFTOKEN/22012253/index.html

14. http://www.nanotechproject.org/inventories/consumer/

15. Patra, H. Synthetic nanoforms as designer and explorer for cellular events, 2011.

WEB:http://www.caluniv.ac.in/opac/detail3.php?qRecNo=CL10021 $\mathrm{P} \& q \mathrm{SrNo}=\mathrm{CL} \& q$ Type $=\mathrm{P}$

16. Hwang, D. and Bradley, J. Lux Research. 2010.

WEB: http://www.electroiq.com/articles/stm/2010/04/the-recessions-ripple.html

17. Striolo, A., \& Luu, X. Bulletin of the American Physical Society. 2013.

WEB: http://meetings.aps.org/Meeting/MAR13/Session/Q1.96

18. Poda, A.; Kennedy, A. \& Bednar, A. Nanotechnology, 2012, 319. ISBN: 978-1-4665-6276-9

19. Patra, H.; GuhaSarkar, D.; \& Dasgupta, A. Analytica chimica acta. 2009,649, 128 .

DOI: $10.1016 / \mathrm{j} . \mathrm{aca} .2009 .07 .012$

20. Li, Y.; Yang, X.; Feng, Y.; Yuan, Z.; \& Su, B. Critical Reviews in Solid State and Materials Sciences. 2012, 37, 1.

DOI: $10.1080 / 10408436.2011 .606512$

21. Devan, R.; Patil, R.; Lin, J. \& Ma, Y. Advanced Functional Materials. 2012, 22, 3326.

DOI: $10.1002 /$ adfm.201201008

22. Sysoev, V.; Strelcov, E.; \& Kolmakov, A. In Metal Oxide Nanomaterials for Chemical Sensors. 2012, Springer New York 465. DOI: $10.1007 / 978-1-4614-5395-6 \quad 15$

23. Alibabaei, L.; Luo, H.; House, R.; Hoertz, P.; Lopez, R. \& Meyer, T. Journal of Materials Chemistry A. 2013, 1, 4133.

DOI: $10.1039 / \mathrm{C} 2 \mathrm{TA00935H}$

24. Patra, H. \& Dasgupta, A. Nanomedicine: Nanotechnology, Biology and Medicine. 2012, 8,842 .

DOI: $10.1016 /$ j.nano.2011.10.009

25. Fischer, H. \& Chan, W. Current opinion in biotechnology. 2007, 18, 565

DOI: $10.1016 /$ j.copbio.2007.11.008

26. Chithrani, B.; Ghazani, A. \& Chan, W. Nano letters. 2006, 6, 662. DOI: $10.1021 / \mathrm{n} 10523960$

27. Jiang, W.; Kim, B.; Rutka, J. \& Chan, W. Nature Nanotechnology. 2008, 3,145 .

DOI: $10.1038 /$ nnano. 2008.30

28. Yang, K.; Feng, L.; Shi, X. \& Liu, Z. Chemical Society Reviews. 2013, 42, 530 .

DOI: $10.1039 / \mathrm{C} 2 \mathrm{CS} 35342 \mathrm{C}$

29. Zhang, M.; Yamaguchi, T.; Iijima, S. \& Yudasaka, M. Nanomedicine: Nanotechnology, Biology and Medicine. 2013, 5, 657. DOI:10.1016/j.nano.2012.11.011

30. Martinelli, V.; Cellot, G.; Toma, F.; Long, C.; Caldwell, J.; Zentilin, L. \& Mestroni, L. ACS nano. 2013
DOI: $10.1021 / \mathrm{nn} 4002193$

31. Usui, Y.; Aoki, K.; Narita, N.; Murakami, N.; Nakamura, I.; Nakamura, K. \& Saito, N. Small. 2008, 4, 240

DOI: $10.1002 / \mathrm{smll} .200700670$

32. Porter, A.; Gass, M.; Muller, K.; Skepper, J.; Midgley, P. \& Welland, M. Nature Nanotechnology. 2007, 2, 713 .

DOI: 10.1038 /nnano.2007.347

33. Zhang, Y.; Ali, S.; Dervishi, E.; Xu, Y.; Li, Z.; Casciano, D. \& Biris, A. Acs Nano. 2010, 4, 3181.

DOI: $10.1021 / \mathrm{nn} 1007176$

34. Tian, B.; Wang, C.; Zhang, S.; Feng, L.; \& Liu, Z. ACS nano. 2011 5,7000 .

DOI: $10.1021 / \mathrm{nn} 201560 \mathrm{~b}$

35. Crich, S.; Alberti, D.; Orio, L.; Stefania, R.; Longo, D. \& Aime, S. Current Cardiovascular Imaging Reports. 2013, 6, 69.

DOI: $10.1007 / \mathrm{s} 12410-012-9180-2$

36. Contreras, E.; Cho, M.; Zhu, H.; Puppala, H.; Escalera, G.; Zhong, W. \& Colvin, V. Environmental science \& technology. 2013, 47, 1148. DOI: $\underline{10.1021 / \mathrm{es} 3036785}$

37. Xiaoshan, Z.; Lin, Z.; Zhenghua, D.; Ruiqi, Q.; Yan, L. \& Yupeng, L. Journal of Environmental Science and Health Part A. 2008, 43, 278. DOI: $10.1080 / 10934520701792779$

38. Wu, S.; Huang, L.; Head, J.; Chen, D.; Kong, I. \& Tang, Y. J Pet Environ Biotechnol. 2012, 3, 126.

DOI: $10.4172 / 2157-7463.1000126$

39. Hui, Y.; Chao, L.; Danfeng, Y.; Huashan, Z. \& Zhuge, X. J. Appl. Toxicol. 2009, 29, 69 .

DOI: $10.1002 /$ jat. 1385

40. Yue, W.; Chiheng, W. \& Robert, S. Materials. 2010, 3, 4842 DOI: $10.3390 / \mathrm{ma} 3104842$

41. Robert, L.; Lan, M.; Alexandra, K.; Daniela, H.; Jurgen, S.; Karin, W. \& Wendel, W. Adv. Mater. 2010, 22, 2601

DOI: $10.1002 / \mathrm{adma} .200902658$

42. Fond, A. \& Meyer, G. Nanotechnologies for the Life Sciences. 2010 DOI: $10.1002 / 9783527610419 . n t 1 s 0048$

43. Rasmussen, J.; Martinez, E.; Louka, P. \& Wingett, D. Expert opinion on drug delivery. 2010, 7, 1063. DOI: $10.1517 / 17425247.2010 .502560$

44. Adams, L.; Lyon, D. \& Alvarez, P. Water research. 2006, 40, 3527. DOI: $10.1016 /$ j.watres.2006.08.004

45. Colvin, V. Nature biotechnology. 2003, 21, 1166 DOI: $\underline{10.1038 / \mathrm{nbt} 875}$

46. Hoffmann, M.; Martin, S.; Choi, W. \& Bahnemann, D. Chemical reviews. 1995, 95, 69 DOI: $10.1021 / \mathrm{cr} 00033 \mathrm{a} 004$

47. Berger, T.; Sterrer, M.; Diwald, O.; Knözinger, E.; Panayotov, D.; Thompson, T. \& Yates, J. The Journal of Physical Chemistry B. 2005, 109, 6061 DOI: $10.1021 / \mathrm{jp} 0404293$

48. Mills, A. \& Le Hunte, S. J Photochem Photobiol. Chemistry. 1997, $108,1$.

DOI: $16 / \mathrm{S} 1010-6030(97) 00118-4$

49. Applerot, G.; Lipovsky, A.; Dror, R.; Perkas, N.; Nitzan, Y.; Lubart, R. \& Gedanken, A. Advanced Functional Materials. 2009, 19, 842. DOI: $10.1002 / \mathrm{adfm} .200801081$

50. Brunet, L.; Lyon, D.; Hotze, E.; Alvarez, P. \& Wiesner, M. Environmental science \& technology. 2009, 43, 4355. DOI: $10.1021 / \mathrm{es} 803093 \mathrm{t}$

51. Sayes, C.; Wahi, R.; Kurian, P.; Liu, Y.; West, J.; Ausman, K. \& Colvin, V. Toxicological Sciences. 2006, 92, 174. DOI: $10.1093 /$ toxsci/kfj197

52. Wu, N.; Wang, J.; Tafen, D.; Wang, H.; Zheng, J.; Lewis, J. \& Manivannan, A. Journal of the American Chemical Society. 2010, 132,6679 .

DOI: $\underline{10.1021 / \mathrm{ja} 909456 \mathrm{f}}$

53. Pitkethly, M. Materials Today. 2004, 7, 20. DOI: $10.1016 /$ S1369-7021(04)00627-3

54. Klaine, S.; Alvarez, P.; Batley, G.; Fernandes, T.; Handy, R.; Lyon, D. \& Lead, J. Environmental Toxicology and Chemistry. 2008, 27, 1825 .

DOI: $10.1897 / 08-090.1$

55. Sinha, R.; Karan, R.; Sinha, A. \& Khare, S. Bioresource technology. 2011, 102, 1516

DOI: $10.1016 / j$. biortech.2010.07.117

56. Jennings, V.; Rayner-Brandes, M. \& Bird, D. Water research. 2001, 35,3448 
DOI: $10.1016 / \mathrm{S} 0043-1354(01) 00067-7$

57. Sun, T. \& Stahr, H. Journal of AOAC International. 1993, 76, 893.

58. Zheng, H.; Liu, L.; Lu, Y.; Long, Y.; Wang, L.; Ho, K. \& Wong, K. Analytical Sciences. 2010, 26, 125. DOI: $10.2116 /$ analsci.26.125

59. Maron, D. \& Ames, B. Mutation Research/Environmental Mutagenesis and Related Subjects. 1983, 113, 173.

DOI: $10.1016 / 0165-1161(83) 90010-9$

60. Sun, T.; Stahr, H. \& Love, J. Journal of agricultural and food chemistry. 1998, 46, 2682. DOI: $10.1021 / \mathrm{jf} 970647 \mathrm{~b}$

61. Mori, T.; Takada, H.; Ito, S.; Matsubayashi, K.; Miwa, N. \& Sawaguchi, T. Toxicology. 2006, 225, 48.

DOI: $10.1016 /$ j.tox.2006.05.001

62. Pan, X.; Redding, J.; Wiley, P.; Wen, L.; McConnell, J. \& Zhang, B. Chemosphere. 2010, 79, 113.

DOI: $10.1016 / \mathrm{j}$.chemosphere.2009.12.056

63. Parial, D.; Patra, H.; Dasgupta, A. \& Pal, R. European Journal of Phycology. 2012, 47, 22. DOI: $\underline{10.1080 / 09670262.2011 .653406}$

64. Parial, D.; Patra, H.; Roychoudhury, P.; Dasgupta, A. \& Pal, R. Journal of Applied Phycology. 2012, 24, 55.

DOI: $10.1007 / \mathrm{s} 10811-010-9645-0$

65. Patra, H. \& Dasgupta, A. Advanced Science Letters. 2011, 4, 11. DOI: $\underline{10.1166 / a s l .2011 .3163}$

66. Sengupta, J.; Datta, P.; Patra, H.; Dasgupta, A. \& Gomes, A. Journal of Nanoscience and Nanotechnology. 2013, 13, 1660. DOI: $\underline{10.1166 / \text { inn.2013.7113 }}$
67. Patra, H.; Banerjee, S.; Chaudhuri, U.; Lahiri, P. \& Dasgupta, A. Nanomedicine: Nanotechnology, Biology and Medicine. 2007, 3, 111. DOI: $10.1016 /$ j.nano.2007.03.005

68. Zhao, Y.; Sun, X.; Zhang, G.; Trewyn, B.; Slowing, I. \& Lin, V. ACS nano. 2011, 5, 1366

DOI: $10.1039 / \mathrm{C} 2 \mathrm{RA} 22264 \mathrm{G}$

69. Sahoo, D.; Bhattacharya, P.; Patra, H.; Mandal, P. \& Chakravorti, S. Journal of nanoparticle research. 2011, 13, 6755. DOI: $10.1007 / \mathrm{s} 11051-011-0583-9$

70. Deb, S.; Patra, H.; Lahiri, P.; Dasgupta, A.; Chakrabarti, K. \& Chaudhuri, U. Nanomedicine: Nanotechnology, Biology and Medicine. 2011, 7, 376 DOI: $10.1016 /$ i.nano.2011.01.007

71. Rothen-Rutishauser, B.; Schürch, S.; Haenni, B.; Kapp, N. \& Gehr, P. Environmental science \& technology. 2006, 40, 4353. DOI: $10.1021 / \mathrm{es} 0522635$

72. Deb, S.; Chatterjee, M.; Bhattacharya, J.; Lahiri, P.; Chaudhuri, U.; Choudhuri, S. \& Dasgupta, A. Nanotoxicology. 2007, 1, 93. DOI: $10.1080 / 17435390600772978$

73. De Paoli Lacerda, S.; Park, J.; Meuse, C.; Pristinski, D.; Becker, M. L.; Karim, A.; Douglas, J. ACS Nano. 2010, 4, 365. DOI: $10.1021 / \mathrm{nn} 9011187$

74. Deb, S.; Raja, S.; Dasgupta, A.; Sarkar, R.; Chattopadhyay, A.; Chaudhuri, U. \& Sardar, P. Blood Cells, Molecules, and Diseases. 2012, 48,36 DOI: $10.1016 / \mathrm{j}$. bcmd.2011.09.011

75. Semberova, J.; De Paoli Lacerda, S.; Simakova, O.; Holada, K.; Gelderman, M.; Simak, J. Nano Lett. 2009, 9, 3312 DOI: $\underline{10.1021 / \mathrm{nl} 901603 \mathrm{k}}$

\section{Advanced Materials Letters}

\section{Publish your article in this journal}

ADVANCED MATERIALS Letters is an international journal published quarterly. The journal is intended to provide top-quality peer-reviewed research papers in the fascinating field of materials science particularly in the area of structure, synthesis and processing, characterization, advanced-state properties, and applications of materials. All articles are indexed on various databases including DOAJ and are available for download for free. The manuscript management system is completely electronic and has fast and fair peer-review process. The journal includes review articles, research articles, notes, letter to editor and short communications.

\section{JOURNAL}

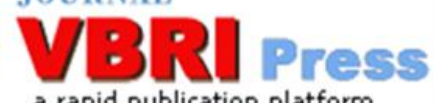

a rapid publication platform

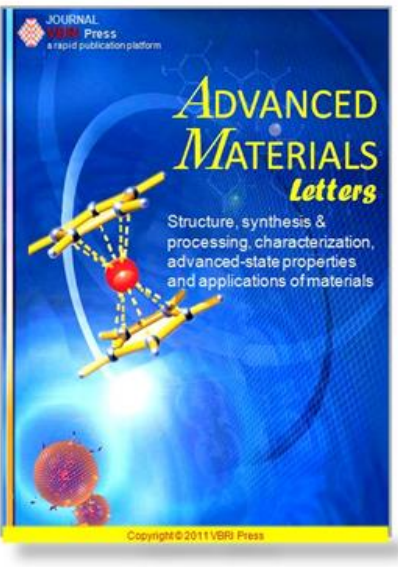

